\author{
Sławomir Wacewicz \\ Center for Language Evolution Studies (CLES); Department of English \\ Nicolaus Copernicus University \\ wacewicz@umk.pl \\ Przemysław Żywiczyński \\ Center for Language Evolution Studies (CLES); Department of English \\ Nicolaus Copernicus University
}

\title{
From the narrow to the broad. Multiple perspectives on language evolution.
}

\begin{abstract}
Although many of the recent controversies in the field of language evolution research are empirical, the deepest divides seem to remain theoretical in nature. Specifically, defining language in incompatible ways has led to radically different views on language evolution as a programme, including evaluation of its current success and future progress. Despite recent manifestos from the "narrow" camp (Hauser et al. 2014; Bolhuis et al. 2014), who along the lines of Hauser, Chomsky and Fitch (2002) equates language with the syntactic processor, the rival approach seems to be gaining momentum. It embodies a move in exactly the opposite direction, by understanding language broadly and assuming an inclusive perspective on its origins, which results in ongoing expansion of the field of language evolution. New areas of academic reflection (such as normativity) are being brought to bear, new areas of linguistics are being included (such as pragmatics or linguistic politeness); and, interestingly, existing linguistic methods are now being used to inform animal communication studies.
\end{abstract}

Keywords: language evolution, evolution of language, faculty of language, FLN, FLB, biolinguistics, biosemiotics 


\section{Introduction}

Many of the recent controversies in the field of language evolution the modern study of language origins - bear the hallmarks of empirical problems amenable to the methods of the Kuhnian normal science. This dayto-day "puzzle solving" may not be able to give us any "big" answers in the near future, but it is yielding a wealth of evidence to evaluate the competing hypotheses and weigh them against each other in an informed way. Were the Neandertals able to speak? The debate continues, but converging evidence (e.g. Johansson 2012, Dediu and Levinson 2013) systematically favours that possibility. Was there a gestural rather than vocal protolanguage? Semiotic experiments such as those by Fay et al. (2013) $)^{1}$ combined with data from e.g. primate communication (e.g. Slocombe et al. 2011) provide good reasons to believe that the first language-like communicative system could indeed rely on a significant visual component.

Interestingly, however, some of the deepest controversies in language evolution are not due to the shortage of good evidence, but rather result directly from the foundational theoretical problems. "Your theory of language evolution depends on your theory of language", the title of a chapter by Ray Jackendoff (2010), may also be the most accurate summary of the status quo in this field of research: the deepest divide lies in defining the central notion of interest. In "Discussing the evolution of the assorted beasts called language", Rudolf Botha (2000) offers a useful point in case: reading through the volume resulting from the first Evolang conference, he lists thirteen different conceptualisations of language, from a "process" to a "skill", to an "activity", to a "contract". If we wanted a unifying dimension for organising all this diversity and the resulting difference of opinion, probably the most useful systematising polarity would be that between a narrow and an inclusive views.

\section{Narrowing language down}

The biolinguist has a quick but powerful fix. Prototypically, science deals with problems that are well-defined and tractable, so if we want language origin to enjoy the status of a scientifically legitimate and respectable question, we must pare down the all-encompassing and thus unwieldy

\footnotetext{
1 Which, notably, are informative in their own right, that is independently of the "origins" question.
} 
notion of language to something of manageable proportions, preferably open to formalisation. In other words, the scientific way is to narrow language down to its bare computational bones, making it roughly synonymous with syntax $^{2}$. The conceptualisation of choice is distinctly along the lines of the Chomskyan linguistic tradition, and the most important programmatic text is the influential 2002 paper by Hauser, Chomsky and Fitch (Hauser et al. 2002). On this view, language (narrowly defined) is the "computational core" responsible for "discrete infinity"- the recursively combinatorial potential characteristic of human verbal communication. Primarily, it is a cognitive capacity, but in an evolutionary sense the "language faculty" can be understood as a genetic constitution of an organism that gives rise to the cognitive capacity in the course of normal ontogenetic development. In this evolutionary sense, FLN, or language faculty narrowly understood, is a phylogenetically novel, biological trait.

What is important, Hauser et al. (2002) is commonly but erroneously thought to define FLN as ,what is both uniquely human and uniquely linguistic". In fact, the definition of FLN in the 2002 text is unequivocally as "the computational core", with additional hypotheses that this computational core may be uniquely human and may consist only of recursion. The "uniquely human + uniquely linguistic" definition of FLN was only proposed three years later in a follow-up text by the same authors (Fitch et al. 2005). The fact that those authors never retracted the 2002 version lead to the two definitions functioning side by side, resulting in a regrettable terminological mess - see Wacewicz (2012) for discussion.

To someone interested in staking out the scientifically legitimate territory by equating it with the study of FLN, this definitional move has two parts. Firstly, it tells us what language is: the combinatorial machinery responsible for generating the discrete and hierarchically structured infinity of human linguistic expression, the computational core that is relatively tangible and formalizable. The biolinguistics formalisation almost obligatorily refers to the apparatus of the Minimalist Programme, leading critics to suspect "that 'biolinguistics' may turn out to be merely a more scientific-sounding term for generative minimalism" (Bickerton 2014: 74).

2 Cf. e.g. Bolhuis, Tattersall, Chomsky and Berwick (2014): "In our view, for the purposes of scientific understanding, language should be understood as a particular computational cognitive system, implemented neurally, that cannot be equated with an excessively expansive notion of $<$ language as communication $>$." "In place of a complex rule system or accounts grounded on general notions of $<$ culture $>$ or $<$ communication, $>$ it appears that $h u$ man language syntax can be defined in an extremely simple way that makes conventional evolutionary explanations much simpler." 
But equally if not more important is the negative proposal: what language is not. Such a stance generates a sizeable list of "FLB" capacities (extended working memory, extended Theory of Mind, mental time travel and displaced representation, vocal imitation, cooperation with non-kin, etc.) and other phenomena that supposedly do not qualify into the lawful bounds; that is, at least not under the term of the evolution of language.

Not surprisingly, this negative stance is well reflected in the criticism of the mainstream language evolution research, to which the "narrow" ("biolinguistics") camp is committed. As a particularly telling example, Hauser, Chomsky, Lewontin and others (Hauser et al. 2014) posit that:

“(1) studies of nonhuman animals provide virtually no relevant parallels to human linguistic communication, and none to the underlying biological capacity; (2) the fossil and archaeological evidence does not inform our understanding of the computations and representations of our earliest ancestors... (3) our understanding of the genetics of language is so impoverished that there is little hope of connecting genes to linguistic processes any time soon; (4) all modeling attempts have made unfounded assumptions, and have provided no empirical tests, thus leaving any insights into language's origins unverifiable."

Many of the problems highlighted by the recent statements from the Chomskyan camp (Hauser et al. 2014; Bolhuis et al. 2014) seem to be, in one way or another, a throwback to the influential text by Richard Lewontin (1998), "The evolution of cognition: Questions we will never answer". Over a decade ago, Lewontin formulated a sceptical manifesto, pointing to numerous weaknesses in the chain of inferences from available evidence to adaptive (selection-based) accounts of the evolutionary emergence of particular cognitive traits. The reservations included poor definition of most cognitive traits, poor mapping to the biological (neuronal, genetic) correlates, their loose correspondence to the criteria for natural selection (such as heritability or measurable fitness advantage), and lack of direct evidence for function; plus scant fossil evidence and limited and partly inadequate comparative evidence. Symptomatically, a rhetorical

3 This general sentiment is probably best summarized in Noam Chomsky's words at a UCL seminar, 10 October 2011: "There is a field called evolution of language, which has a burgeoning literature, most of which in my view is total nonsense." (see e.g. http:// linguistlist.org/issues/22/22-4631.html or http://www.evolutionarylinguistics.org/home/ chomsky-on-language-evolution for reference) 
question that he asks near the end of the text is "Why is anyone interested in the evolution of human cognition?"

But this sceptical attitude, if treated seriously, could write off a majority of sciences whose inferences go beyond strict formalisation. In 2014, the genetic and fossil evidence is much richer, including well established evidence of fire domestication from at least 700 kya (e.g. Roebroeks and Villa 2011), contra Lewontin's (1998: 124) estimate of 100 kya, and comparative evidence is unimaginably more complete than the 1998 state of art. As to the definitions and operationalization of cognitive traits, this pertains equally well to any other cognitive science, but if anything, it is scientific theory that has a duty to track everyday meaning rather than vice versa. Scientific theory has every right to coin new technical terms but not to reach out to natural language to tamper with and impose on its established use, precisely what the syntactocentric theory is trying to do with "language". Finally, the "why bother" question is just as relevant to the studies in great many other fields of basic research, so it cannot be used as an argument, unless we are prepared to let go of such disciplines as history or palaeontology.

\section{The broad way - language evolution as an expanding field}

Unsurprisingly, the "narrow", or biolinguistic, perspective as outlined above, is now a minority position in the field. This is related to its major drawback: outside of a narrowly defined perspective, this restrictive notion of language is simply not particularly interesting. Put differently, even a relatively complete answer about the emergence of FLN would hardly serve as a satisfactory explanation of the language origins problem in the form that is interesting to most people. When the question of the origin of language is posed as one of the foundational human questions, the notion of language there is definitely not the narrow sense appropriated by a syntactician. Features or phenomena such as common ground and online coordination, intersubjectivity, collective intentionality, massively cooperative exchange of information, mimetic communication, and multimodal proto-sign, may not be narrowly linguistic but are certainly preconditions for verbal communication, and are definitely the kinds of things about whose origins we would like to know. It is not clear what cognitive gains are supposed to result calling syntax "language" and ignoring the remaining aspects of human verbal communication (rather than, for example, studying the emergence of syntax and the emergence of language as parallel but interrelated projects). 
Importantly, however, the "broad" view is getting broader. Insisting on the lexicon or aspects of phonetics and phonology as inalienably linguistic (and possibly unique to humans), as Pinker and Jackendoff (2005) did, is just a first step. Capacities that are inherently linguistic do not stop at syntax and its semantic/intentional and sensorimotor interfaces. Pragmatics is one example. Although - for reasons mostly related to theoretical prejudice until recently it was neglected in the origins context ${ }^{4}$, a growing number of authors turn our attention to the basic fact that understanding of human communication rests on a rich pragmatic scaffolding (Scott-Phillips 2014, Adornetti and Ferretti, 2014 [this volume]). Linguistic politeness, an area that the standard view would see as totally peripheral, is also calling for attention from a naturalistic, evolutionary perspective (Wacewicz et al., 2014 [this volume]).

Going beyond FLN does not mean simply adding more individuallevel capacities, but something more fundamental: stepping outside a single person's mind and body to acknowledging language as a super-individual phenomenon. What Chomsky would call "E-language" may be external, but not epiphenomenal. There is a growing conviction, for example, that cultural evolution (e.g. Kirby et al. 2008) is not something second-order, kicking in only after we have biologically evolved (to use Arbib's [2006] term) a "language-ready brain"; rather, language itself, as much as an individual capacity, is a cultural selection niche.

All of this is now being complemented with a move in the other direction. So far, language evolution accounts have benefitted enormously from a wealth of data on animal communication and cognition from comparative biologists and psychologists. But now, specifically linguistic techniques and methodologies are being deployed to analyze animal communication (and cognition). Examples include an application of Wierzbicka's Natural Semantic Metalanguage to the study of conceptual repertoires in chimpanzees (Wierzbicka 2014: 156-182), examination of patterns of turn-taking in monkey vocalisations (Takahashi et al. 2013), semantic-pragmatic analysis of roots and affixes in Campbell's monkey's alarm calls (Schlenker et al., in press), and the general controversy regarding the applicability of a linguistic-morphological analysis to monkey calls (cf. Ouattara et al. 2009, Barceló-Coblijn and Gomila 2012).

4 Scott-Phillips (2014) observes that The Oxford Handbook of Language Evolution (ed. Gibson and Tallerman 2011) lists 8 pages under "pragmatics", compared to 213 for "syntax". 


\section{Multiple perspectives on language origins}

The present issue of Theoria et Historia Scientiarum is comprised of texts which - both individually and as a collective - unambiguously vote in favour of the latter approach. This is particularly visible in the first part of the volume, where each of the papers supports the inclusive perspective on language evolution directly, by making a case for the relevance of a particular linguistic aspect, phenomenon, or methodology. Michael Pleyer and James Winters (2014) put forward a case for a closer integration of Cognitive Linguistics into language evolution research, and Maciej Pokornowski (2014), in turn, calls for a closer rapprochement between language evolution and data science, specifically big text data. Ines Adornetti and Francesco Ferretti (2014) advance a pragmatic, action-oriented account of language emergence which takes into consideration the embodiment and embeddedness of human communication. Finally Sławomir Wacewicz et al. (2014) show the phenomenon of linguistic politeness, a neglected one in language evolution research, to clearly belong into the realm of naturalistic, evolutionary study.

The "inclusive" line continues in the second part of the volume, with the text by Daniela Lenti-Boero (2014), who demonstrates how early infant vocalization can be useful in informing research on the origins of speech. Speech is also the topic of Magdalena Igras et al. (2014), who propose a new approach to using phoneme inventories for tracing back language phylogenies. Till Nikolaus von Heiseler (2014) and Joel Parthemore (2014) both present new hypotheses: the former on the role of storytelling in language evolution, the latter on protoconcepts, onto- and phylogenetically basic units of prelinguistic but conceptual thought. The volume is concluded with two reviews - by Agnieszka Dębska (2014) and by Sławomir Wacewicz (2014) - both of books that explicitly refer to the social context and social origin of human communication.

\subsection{New directions}

Pleyer and Winters (2014) put forward the point that "we can gain important insights on the evolution of language and cognition by integrating evolutionary linguistics and the framework of Cognitive Linguistics [(CL)]". Their discussion focuses on two trends in CL: usage-based approaches, which view language structures as arising through abstraction from individual communicative events (Bybee 2010; Ellis 2013), and Construction Grammar with its notion of language as "a structured inventory or network 
of constructions $[\ldots]$ defined as form-meaning pairings with varying degrees of schematicity [...]" (Goldberg 2006, Hilpert 2014). When interpreted as complex adaptive systems (Beckner et al. 2009: 2), the description of linguistic process afforded by usage-based approaches and Construction Grammar can, according to Pleyer and Winters, help understand the evolution of language in the three scales identified by Kirby (2012, mentioned earlier in Kirby and Hurford 2002) - the ontogenetic timescale of individuals acquiring language, the glossogenetic timescale of historical language change and the phylogenetic timescale of the evolution of the species. In drafting their proposal for the synthesis of CL and evolutionary linguistics, the authors identify the common interest of the two fields in "the cognitive machinery [...] of language and use", which helps account for the change of language systems and, if studied with regard to its biological prerequisites, can - as Pleyer and Winters hope - shed light on how language emerged in the first place.

In a similar vein, Pokornowski (2014) argues for a "closer interaction between data science and evolutionary linguistics". He observes that the emerging field of Big Data has not yet benefitted from the interest of evolutionarily inclined linguists, and that the vast and quickly growing resources of digitalised language are becoming an important but relatively unexplored type of material for testing evolutionary hypotheses. Pokornowski then turns to Twitter as a paragon example of a massive open-access body of authentic language dataripe for investigation, including evolutionarilyinspired investigation. His claim is substantiated by putting forward a model, inspired by the Iterated Learning tradition, for studying the quasievolutionary changes at the level of topic-specific sublanguages on Twitter, with possibilities for extension to other social media sites.

Also in line with a broad and inclusive perspective on the study of language origins, Adornetti and Ferretti (2014) speak out against narrow views on language, such as the Chomskyan syntactocentric tradition or the code model. These authors underscore the grounding of language in context: to human users, language is not an abstract, disembodied processing machine, but a tool for interaction of real, flesh-and-blood agents, which they use in a specific external environment to achieve pragmatic communicative success. On Adornetti and Ferretti's analysis, embracing a less abstract and more action-oriented and embedded account of language goes hand in hand with arguments for the gestural rather than vocal origin of human symbolic communication. Their claims are fleshed out with references to rich empirical work on the mirror system in primates.

Wacewicz, Żywiczyński and McCrohon (2014) turn their attention to linguistic politeness, a phenomenon almost non-existent in evolutionary- 
linguistic literature. They point to the fact that linguistic politeness acts as an interface between language and the "core questions of human ethology and human behavioural ecology", such as normativity, cooperation and group hierarchy. While they do take note of the substantial difficulties in investigating politeness - for example, problems with an unambiguous definition, operationalization and measuring of politeness, and respecting the vast intercultural differences - they conclude that linguistic politeness deserves a place on a naturalistically oriented research agenda. Among the most interesting questions Wacewicz et al. point to is that of the evolutionary stability of politeness, which seems to be a consistently beneficial signal despite being "cheap" and manipulable.

\subsection{New solutions}

Lenti Boero proposes how arguments from developmental psychology, specifically those that relate to human vocal behaviours, can inform the research on early, protolinguistic, beginnings of language. Careful to avoid the recapitulationist fallacy, Lenti Boero examines the developmental pathway of human infants - from the earliest stage characterized by crying through musibabling (her own concept referring to infants' engagement in protophonic productions) until the onset of the universal speech perception at the age of six months - in search for the vocal precursors of language. In doing so, she appeals to the arguments both from parental selection (Locke 2006) and sexual selection (as envisaged by Darwin 1871 and later by Mithen 2006, 2009). Her paper also contains an interesting discussion on vocal mimicry and the viability of onomatopoeic protolanguage in the light of neurocognitive research (Hashimoto et al. 2006).

The paper by Igras et al. (2014) deals with measuring phonemic inventories in languages and the possibilities of applying this knowledge to inform research on language phylogenies. This approach was pioneered by Atkinson (2011), who suggested that the notion of founder effect from population genetics could be applied to tracing back migrations of populations of language users across considerable time scales. Igras et al. compiled a database with audio material from over 3500 languages, relying mostly on the material from the Global Recording Network but complemented with other sources. They have been developing methods of automated segmentation of this data into phonemes and computing distances between languages; despite initial equivocal results, they are aiming to bring this methodology to bear on the linguistic serial founder debate. 
Von Heiseler's starting point is the idea of atypically fast evolution in the hominin line, with recent research indicating that the development of cognitive abilities in our ancestors was accelerated about 16 times compared to other primates. This suggests a discontinuity in the evolutionary process comparable to the emergence of sexual reproduction or the cell nucleus: a major transition in evolution. In this new framework, he proposes the following hypothesis: a completely new system developed, one that created its own elements in the form of human beings, language, and culture. This new evolutionary system consists of two feedback loops connected with a backchannel between them, and the content of this backchannel is displaced action encoded in narration. Although it is difficult to do justice here to von Heiseler's complex proposal, its core is that not only the human brain and language but also most of the unique human faculties (including advanced theory of mind and episodic memory) are adapted almost exclusively to developing the functioning of the backchannel (narration) at a super-fast evolutionary pace. Von Heiseler's account is undoubtedly speculative and controversial, but even if his paper turns on several risky assumptions, it contains a number of daring and innovative proposals.

Parthemore (2014) considers the problem of primacy between languagelike communication (which apparently relies on concepts) and conceptual thought (which on some influential accounts derives from language). Parthemore rejects the radical positions of Fodor's nativism and McDowell's conceptualism to propose his own moderately nativistic Protoconcept Hypothesis, on which human cognition comes innately equipped with a small set of protoconceptual categories, which then give rise to progressively more complex conceptual repertoires. In short, we are innately biased to experience and interact with the world in some ways and not in others, beyond what our embodiment contributes. Basic protoconcepts correspond to some of the most superordinate categories organizing our experience, such as proto-objects, proto-happenings, and proto-properties (in English mapping to the grammatical categories of nouns, verbs, and adjectives and adverbs). Complementing them with several quasi-logical operators would yield "a minimally structured logic both far simpler and at the same time far more expressively powerful than existing formal logics" - a system capable of grounding protolanguage.

\subsection{The social dimension}

Increasingly many recent publications on language origins refer to the social perspective (e.g. Scott-Phillips 2014, Dunbar et al. [ed] 2014). Dębska 
(2014) reviews one of them, The Evolution of Social Communication in Primates (ed. Pina and Gontier 2014). Rather than offering a point-bypoint report on the book, Dębska identifies and developssome of the threads in the book that "define the key points of the current debate on language evolution", such as the flexibility vocalisation in apes or the extent of their Theory-of-Mind capacities. Dębska's specific focus is on the surprisingly complex communicative behaviour that pointing turns out to be. She discusses the differences of perspective between contributors to the volume, mirroring those in the field at large, as to whether (untrained) chimpanzees and other apes are capable of declarative pointing or of understanding human declarative pointing. Dębska concludes that in this subfield of communication theory "there is a need to develop at least minimal empirical criteria for basic concepts".

Finally, Wacewicz (2014) reviews The social origins of language (ed. Dor, Knight and Lewis 2014), which in his view "aspires [...] to the role of an important programmatic statement". After contemplating the possible definitions of "the social", he turns to the major threads of the book: the problem of honest, cooperative signalling in humans, of cultural evolution, and of the multifaceted nature of language. This last point is particularly important. Wacewicz fully endorses the inclusive outlook on the study of language (origins), which is represented in the reviewed volume and is best captured in a quote from the introduction by the editors (Dor, Knight and Lewis 2014: 2): "more and more of what we learn about language remains confined to specialized professional circles. However, to understand the origin of language requires a move in the opposite direction-a large-scale, collective interdisciplinary effort at theoretical synthesis. [...] Everything counts."

\section{Acknowledgements}

This research was supported by grant UMO-2012/07/E/HS2/00671 from the Polish National Science Centre.

\section{References}

Adornetti, I. and F. Ferretti. (2014) The pragmatic foundations of communication: an action-oriented model of the origin of language. Theoria et Historia Scientiarum 11. 
Arbib, M. A. (2006). Aphasia, apraxia and the evolution of the language-ready brain. Aphasiology 20: 1125-1155.

Atkinson, Q. D. (2011). Phonemic diversity supports a serial founder effect model of language expansion from Africa. Science 332: 346-349.

Barceló-Coblijn, L. and A. Gomila. (2012). Campbell's monkeys alarm calls are not morpheme-based. In Scott-Phillips, T., M. Tamariz, E. Cartmill, J. Hurford (eds.) The Evolution of Language. Proceedings of the 9th International Conference (EVOLANG 9). Singapore: World Scientific, 42-49.

Beckner, C., R. Blythe, J. Bybee, M.H. Christiansen, W. Croft, N.C. Ellis and T. Schoenemann. (2009). Language is a complex adaptive system. Language Learning 59.1: 1-26.

Bickerton, D. (2014). Some Problems for Biolinguistics. Biolinguistics 8: 073-096.

Bolhuis, J. J., I. Tattersall, N. Chomsky and R.C. Berwick. (2014). How could language have evolved? PLoS biology 12.8: e1001934.

Botha, R. P. (2000). Discussing the evolution of the assorted beasts called language. Language and Communication 20.2: 149-160.

Bybee, J. (2010). Language, Usage and Cognition. Cambridge: Cambridge University Press.

Darwin, C. (1871). The Descent of Man, and Selection in relation to Sex. London: Murray.

Dediu, D. and S.C. Levinson. (2013). "On the antiquity of language: the reinterpretation of Neandertal linguistic capacities and its consequences." Frontiers in psychology 4: 1-17.

Dębska, A. (2014). Pointing in the right direction. A discussion of The Evolution of Social Communication in Primates, (eds.). M. Pina and N. Gontier. Theoria et Historia Scientiarum 11.

Dor D., C. Knight and J. Lewis (eds.). (2014). The social origins of language.

Dunbar, R. I. M.,C. Gamble and J.A.J. Gowlett. (2014). (eds.) Lucy to Language: The Benchmark Papers. Oxford: Oxford University Press.

Ellis, N. (2013). Construction Grammar and Second Language Acquisition. In T. Hoffmann and G. Trousdale (eds.), The Oxford Handbook of Construction Grammar. Oxford: Oxford University Press, 365-387.

Fay, N., M. Arbib and S. Garrod. (2013). How to bootstrap a human communication system. Cognitive science 37.7: 1356-1367.

Fitch, T., M. Hauser and N. Chomsky. (2005). The evolution of the language faculty: clarifications and implications. Cognition 97.2: 179-210.

Gibson, K. R. and M. Tallerman. (2011). (eds.). The Oxford Handbook of Language Evolution. Oxford: Oxford University Press.

Goldberg, A. E. (2006). Constructions at work: the nature of generalization in language. Oxford and New York: Oxford University Press.

Hashimoto, T., N. Usui, M. Taira, I. Nose, T. Haji and S. Kojima. (2006). The neural mechanism associated with the processing of onomatopoeic sounds? NeuroImage 31: 1762-1770. 
Hauser, M., N. Chomsky and T. Fitch. (2002). The faculty of language: What is it, who has it, and how did it evolve? Science 298: 1569-1579.

Hauser, M. D., C. Yang, R.C. Berwick, I. Tattersall, M.J. Ryan, J. Watumull, N. Chomsky and R.C. Lewontin. (2014). The mystery of language evolution. Frontiers in psychology, vol. 5.

Hilpert, M. (2014). Construction grammar and its application to English. Edinburgh: Edinburgh University Press.

Igras, M., S. Kacprzak, M. Mąsior and M. Ziółko. (2014). The acoustic diversity in the phoneme inventories of the world's languages. Theoria et Historia Scientiarum 11.

Jackendoff, R. (2010). Your theory of language evolution depends on your theory of language. The Evolution of Human Language: Biolinguistic Perspectives, 63-72.

Johansson, S. (2012). The case for Neanderthal language - how strong is it?, [in:] T. Scott-Phillips, M. Tamariz, E. Cartmill and J. Hurford (red.), The Evolution of Language. Proceedings of the 9th International Conference (EVOLANG 9). New Jersey: World Scientific.

Kirby, S. (2013). The Evolution of Linguistic Replicators. In K. Smith and P.-M. Binder (eds.), The Language Phenomenon: Human Communication from Milliseconds to Millennia, 121-138. London: Springer.

Kirby, S. and J.R. Hurford. (2002). The Emergence of Linguistic Structure: An overview of the Iterated Learning Model. In A. Cangelosi and D. Parisi (eds.), Simulating the Evolution of Language. London: Springer.

Kirby, S., H. Cornish and K. Smith. (2008). Cumulative cultural evolution in the laboratory: An experimental approach to the origins of structure in human language. Proceedings of the National Academy of Sciences 105.31: 1068110686.

Lenti Boero, D. (2014). Sounds of protolanguages: Some preliminary insights from developmental psychology. Theoria et Historia Scientiarum 11.

Lewontin, R. (1998). The evolution of cognition: Questions we will never answer. In D. Scarborough and S. Sternberg (eds.), An invitation to cognitive science, Volume 4: Methods, models, and conceptual issues, 107-132. Cambridge: MIT Press.

Locke, J. L. (2006). Parental selection of vocal behavior. Crying, Cooing, Babbling, and the Evolution of Language. Human Nature 17.2: 155-168.

Mithen, S. (2005). The Singing Neanderthals: the origins of Music, Language, Mind and Body. Cambridge, Mass.: Harvard University Press.

Ouattara, K., A. Lemasson and K. Zuberbühler. (2009). Campbell's monkeysuse affixation to alter call meaning. PloS One 4.11: e7808.

Parthemore, J. (2014). The case for protoconcepts: why concepts, language, and protolanguage all need protoconcepts. Theoria et Historia Scientiarum 11.

Pina, M. And N. Gontier (eds.) (2014). The Evolution of Social Communication in Primates. Lisbon: Springer. 
Pinker, S., Jackendoff, R. (2005). The faculty of language: what's special about it? Cognition 95.2: 201-236.

Pleyer, M. and J. Winters. (2014). Integrating Cognitive Linguistics and Language Evolution Research. Theoria et Historia Scientiarum 11.

Pokornowski, M. (2014). The fourth V, as in evolution: how evolutionary linguistics can contribute to data science. Theoria et Historia Scientiarum 11.

Roebroeks, W. and P. Villa. (2011). On the earliest evidence for habitual use of fire in Europe. PNAS 108.13: 5209-5214.

Schlenker, P., E. Chemla, K. Arnold, A. Lemasson, K. Ouattara, S. Keenan, C. Stephan, R. Ryder and K. Zuberbühler [in press]."Monkey Semantics: Two 'Dialects' of Campbell's Monkey Alarm Calls."

Scott-Phillips, T. C. (2014). Speaking Our Minds: Why human communication is different, and how language evolved to make it special. Palgrave MacMillan.

Slocombe, K., B. Waller and K. Liebal. (2011). The language void: the need for multimodality in primate communication research, Animal Behaviour 81.5: 919-924.

Takahashi D., D.Z. Narayanan and A.A. Ghazanfar. (2013). Coupled oscillator dynamics of vocal turn-taking in monkeys. Current Biology 23.21: 2162-2168.

von Heiseler, T. N. (2014). How language evolved as a backchannel between two feedback loops. Theoria et Historia Scientiarum 11.

Wacewicz, S. (2012). The narrow faculty of language: what is it, who has it, and how is it defined? Theoria et Historia Scientiarum, 9: 217-229.

Wacewicz, S. (2014). The shades of social. A discussion of The social origins of language, (eds.) Dor D., C. Knight and J. Lewis. Theoria et Historia Scientiarum 11.

Wacewicz, S., P. Żywiczyński, L. McCrohon. (2014). „Linguistic politeness from an ethological perspective: Theoretical questions and empirical issues.” Theoria et Historia Scientiarum 11.

Wierzbicka, A. (2014). Imprisoned in English: The hazards of English as a default language. Oxford University Press. 